\title{
A System for Wireless Power Transfer and Data Communication of Long-Term Bio-Monitoring
}

\author{
Enver G. Kilinc, Camilla Baj-Rossi, Sara Ghoreishizadeh, Stefano Riario, Francesca Stradolini, \\ Cristina Boero, Giovanni De Micheli, Fellow, IEEE, Franco Maloberti, Fellow, IEEE, \\ Sandro Carrara, Senior Member, IEEE, and Catherine Dehollain, Member, IEEE
}

\begin{abstract}
A system for wireless power transfer and data communication of implantable bio-monitoring systems is presented. The proposed solution uses a servo-controlled power transmitter moved under the animal moving space. An $x$ - $y$ movable magnetic coil transmits the required power with a level able to keep constant the received energy by the bio-sensor system. The power is transferred via the optimized remote powering link at $13.56 \mathrm{MHz}$. The received ac signal is converted to dc voltage with a passive full-wave integrated rectifier and the voltage regulator supplies $1.8 \mathrm{~V}$ for the implantable sensor system. The sensor control and readout circuit measures the current on the bio-sensors and transmit the data to the transmitter. The sensor data are transmitted to an external reader by a low-power OOK transmitter and received by a custom designed receiver at $869 \mathrm{MHz}$. The results are shown in a tablet computer in real time continuously. The long-term characterization of the implantable system is verified by a fully bio-compatible packaged implant with 30 days measurement. A complete prototype is also presented to prove the overall system performance with the experimental in vitro measurement.
\end{abstract}

Index Terms-Analog circuit design, data communication, implantable biomedical system, integrated circuits, intelligent remote powering, servo-controlled $x$ and $y$ rails, power management, wireless power transfer, bio-sensors, long term continuous monitoring, biocompatible packaging, drug monitoring, glucose monitoring, animal monitoring, animal implant.

\section{INTRODUCTION}

$\mathbf{N}$ OWADAYS, the development of CMOS devices implanted in animals for studies in translational medicine is a common practice in several field of medical research [1].

Manuscript received April 4, 2015; revised July 23, 2015; accepted July 27, 2015. Date of publication July 29, 2015; date of current version September 14, 2015. This work was supported by the Swiss National Funding through Sinergia Initiative. The associate editor coordinating the review of this paper and approving it for publication was Dr. Ashish Pandharipande.

E. G. Kilinc is with the Department of Electrical and Computer Engineering, University of Toronto, Toronto, ON M5S 3G4, Canada (e-mail: enver.kilinc@utoronto.ca).

C. Baj-Rossi, S. Riario, F. Stradolini, G. De Micheli, and S. Carrara are with the Laboratory of Integrated Systems, École Polytechnique Fédérale de Lausanne, Lausanne 1015, Switzerland (e-mail: camilla.baj-rossi@epfl.ch; stefano.riario@epfl.ch; francesca.stradolini@epfl.ch; cristina.boero@epfl.ch; giovanni.demicheli@epfl.ch; sandro.carrara@epfl.ch).

S. Ghoreishizadeh is with the Department of Electrical and Electronic Engineering, Imperial College London, South Kensington SW7 2AZ, U.K. (e-mail: s.ghoreishizadeh14@imperial.ac.uk).

C. Boero is with Bio-Rad Laboratories, 1785 Cressier, Switzerland (e-mail: cristina.boero@epfl.ch).

F. Maloberti is with the Institute of Electrical Engineering, Universitá degli Studi di Pavia, 27100 Pavia, Italy (e-mail: franco.maloberti@unipv.it).

C. Dehollain is with the RFIC Group, École Polytechnique Fédérale de Lausanne, Lausanne 1015, Switzerland (e-mail: catherine.dehollain@epfl.ch).

Color versions of one or more of the figures in this paper are available online at http://ieeexplore.ieee.org.

Digital Object Identifier 10.1109/JSEN.2015.2462362
The development of implantable devices for the telemetry of animal metabolism by monitoring the animal glycemia started two decades ago [2]. However, the large majority of the developments found in literature over these last 20 years is limited on large animal, like pigs [3] or dogs [4], while successful research on small animals, like mice or rats, is mainly focus on brain research [5], or limited to pressure sensors [6] (e.g., no metabolism), or focused on glucose monitoring but with the electronics outside the animal body [7]. On the other hand, the present day VLSI technology and the most recent advances in bio-sensors development allow us to push toward multi-panel platforms that may monitor several endogenous molecules [8] also related to the animal metabolism, meanwhile the use of nano-structures integrated in the sensors allow better performance in the sensors [9] till reaching the ultimate quantum limit in the devices [10]. Along this line of research, it has been very recently presented a completely new, fully-implantable and battery-less device [11] that allows the telemetry of free-moving small mice and several endogenous and exogenous metabolites, including but not limited to glucose, lactate, and the drugs; metoxantrone, etoposide, etodolac.

The reliability of the measurement results changes due to the measurement conditions. If the animal is anesthetized during the measurement, the results are affected from this condition and can vary according to the amount of the anesthesia [12]. Moreover, the measurement under anesthesia can not last for long duration. However, the long-term monitoring is essential for many applications and tracking the progression of the therapy [13]. On the other hand, the animal should be in a natural living space and move freely to reduce the stress on the animal which also influences the measurement results [14], [15].

The implantable systems cannot survive for long duration. There are several issues such as energy source, packaging, lifetime of the sensors, etc. to be solved to increase the lifetime of the implantable system. The most important limitation for the lifetime is energy source for the implantable system. The energy can be supplied to the implantable system by several methods: using transcutaneous cable, battery, power transfer, etc. Using transcutaneous cable for data and power transmission degrades the comfort of the animal [16]. In addition, the cable limits the mobility of the animal and may cause the infections on the animal. Another method can be using rechargeable battery [17], [18]. However, the battery has limited charge \& discharge cycle and needs to be replaced at the end of its life time. Moreover, the battery 


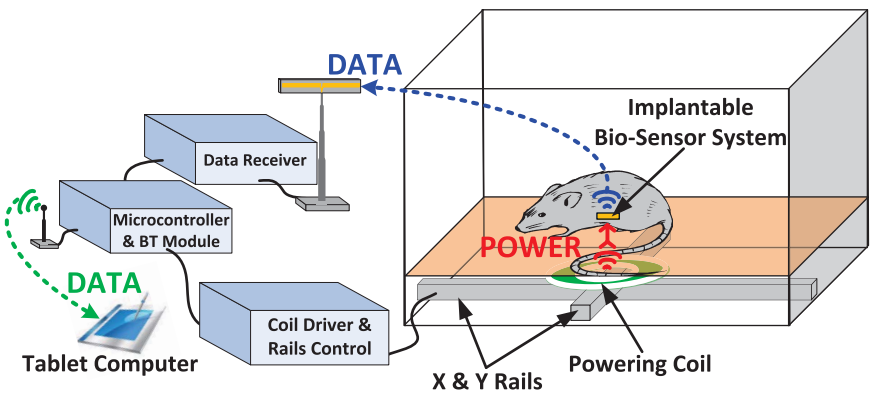

Fig. 1. Miniature concept of wireless power transfer and data communication of the implantable system in a freely moving mouse.

requires more volume and increases the overall weight more if compared to the other components of the implantable system. Especially, the mice are small and light-weight animals and hence the implantable system should be small and light. Therefore, the implantable system must be batteryless and powered wirelessly.

Fig. 1 demonstrates the miniature concept of the wireless power transfer and the data communication of the implantable system in a freely moving mouse. The power is transferred to the implantable system while the animal moves freely inside the living space without disturbing the animal. Additionally, the measurement data is transmitted from the implantable system to an external reader by a second frequency which does not perturb the wireless power transfer performance and allows higher data rate.

The electronic system developed in the frame of this article allows performing in-vitro measurements of Paracetamol and to transmit the measurement results wirelessly to an external reader. Moreover, the results are transmitted through a Bluetooth module from the reader to the tablet computer in order to display the Paracetamol measurements in real-time. The implantable bio-system (bio-sensor interface, power management block, data transmitter) is remotely powered by a servo-controlled $x-y$ rail system. In addition, a dedicated data transmission protocol is proposed to transmit the measurements from the implantable system to the external reader. Finally, long-term in-vitro characterization of the power management block in PBS solution has been performed during 30 days to ensure the performance of the circuits. Section II gives overview about the remotely powered implantable biosensor system. Section III presents the servo-controlled wireless power transfer. Section IV describes the short-range data communication and the Android interface. Section V presents the packaging and long-term characterization of the implant. Section VI demonstrates a case study on continuous long-term monitoring for freely moving rodents which includes the measured results. Finally, Section VII concludes the paper.

\section{REMotely Powered IMPlantable BIO-SENSOR SYSTEM}

The long-term monitoring of vital parameters in the body is essential. The implantable system must be implanted for long duration to develop proper personal medicine for the illness and treat the patient accurately [19]. Fig. 2 shows the block diagram of the remotely powered implantable bio-sensor system.

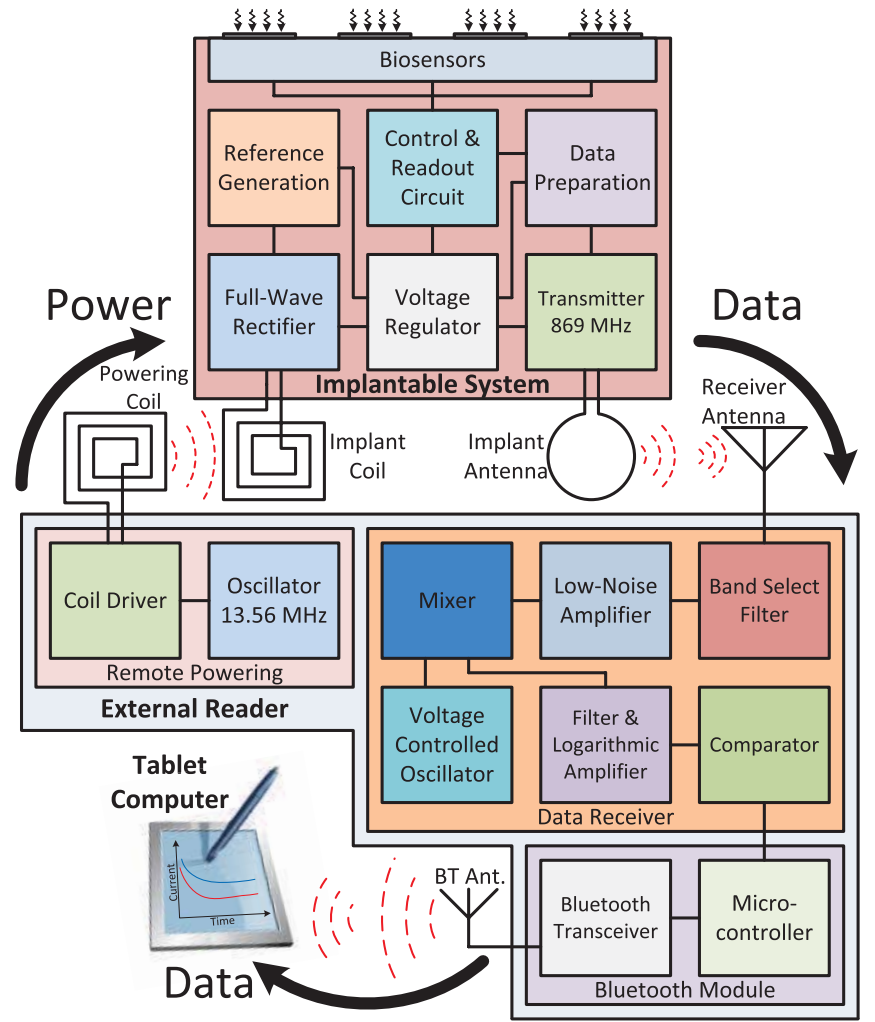

Fig. 2. Block diagram of the remotely powered implantable bio-sensor system.

In this study, the implantable system will be implanted in the abdominal region of a mouse. Accordingly, the distance between the implantable system and the powering coil becomes around $3 \mathrm{~cm}$ due to the housing condition of the animal. The power need to be transferred to the implantable system for 30 days for drug monitoring application while the mouse moves in the living space freely. The overall weight of the implantable system needs to be less than $10 \%$ of the animal weight. Therefore, the implantable system is batteryless which reduces the overall weight and size for the comfort of the animal. The system consists of 3 layers. At the bottom of the system, an implant coil is placed to induce AC voltage from the available magnetic field. The middle layer houses the power management, control \& readout of the bio-sensors, and data communication circuits. The data needs to be transmitted to an external receiver. A low-power data transmitter is required since the received power at the implantable system is limited. The bio-sensors are placed on the top of system to monitor the glucose and drug amount in the vicinity.

\section{A. Power Management Circuits}

The power is transferred wirelessly to the implantable system at $13.56 \mathrm{MHz}$ by using an optimized remote powering link. A passive full-wave rectifier is used to create a DC voltage from the induced AC voltage on the implant coil. Two PMOS transistors are used and connected as diode to rectify the AC signal. The charge-storing technique which allows to reduce the voltage drop between drain and source of the transistor $\left(V_{D S}\right)$ and improve the power efficiency of 


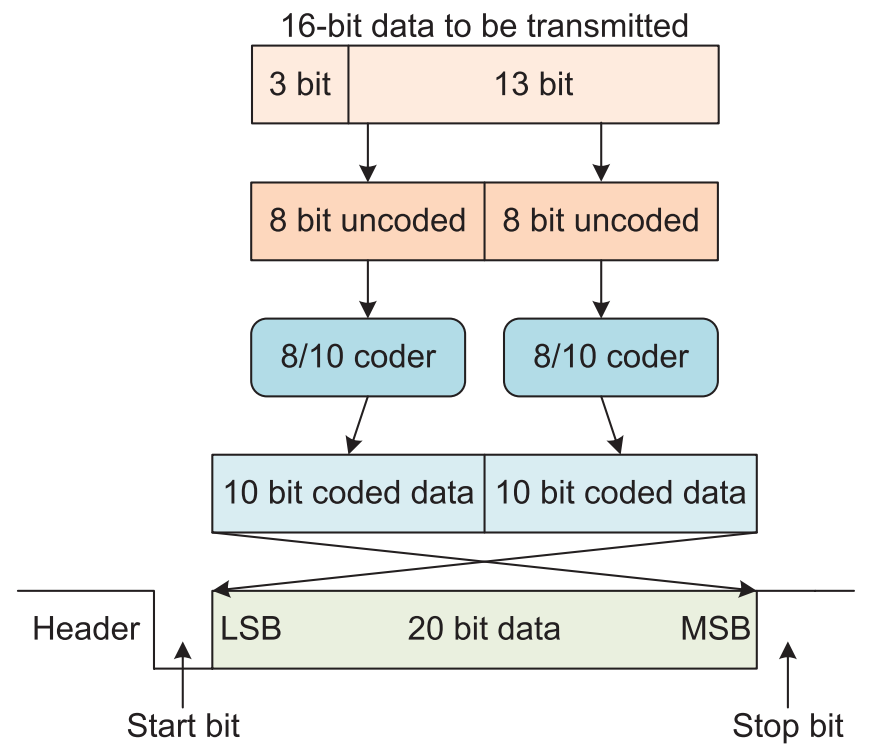

Fig. 3. Data transmission protocol.

the rectifier is used [20]. The rectifier has $80 \%$ of measured power efficiency for $2 \mathrm{~mW}$ load. A low drop-out voltage regulator follows the rectifier to create a noiseless and stable $1.8 \mathrm{~V}$ voltage supply for the implantable system. Power Supply Rejection Ratio (PSRR) of the voltage regulator is more than $60 \mathrm{~dB}$ at $27.12 \mathrm{MHz}$. The reference voltage of the voltage regulator must have also high PSRR value to have acceptable overall PSRR on $1.8 \mathrm{~V}$ voltage supply. The reference generation circuit is a CMOS self-biased reference circuit with a cascode current mirror to improve the PSRR value [20]. The reference generation circuit creates $0.9 \mathrm{~V}$ reference voltage for the voltage regulator and has PSRR value of $78.6 \mathrm{~dB}$ at low frequencies. The digital circuits require a proper reset signal to initialize properly when the supply voltage of the implantable system is insufficient. Therefore, a Power-on-Reset (PoR) circuit is also implemented. The PoR circuit enables and disables all the implantable system at $1.48 \mathrm{~V}$ and $1.45 \mathrm{~V}$, respectively.

\section{B. Control \& Readout Circuits}

The bio-sensors are connected to a mixed-signal interface IC that performs sensor actuation and readout. The IC reads out up to five bio-molecular sensors through different electrochemical detection methods including chronoamperometry (CA) and cyclic voltammetry $(\mathrm{CV})$. Different voltage profiles are generated by using a single fully on-chip reconfigurable waveform generator. The measured sensor current is converted into voltage and is digitized through a second-order sigma delta ADC. The IC is realized in $0.18 \mu \mathrm{m}$ CMOS technology. Electrical measurements show a linear input current range of $1650 \mathrm{nA}$. The IC consumes $0.92 \mathrm{~mW}$ from $1.8 \mathrm{~V}$ supply voltage, making it suitable for remotely powered and implantable applications. More details about the control and readout circuits can be found in [22] and [23].

\section{Data Communication Circuits}

The control and readout IC hosts a data preparation unit that prepares the digitized measured data for transmitting.

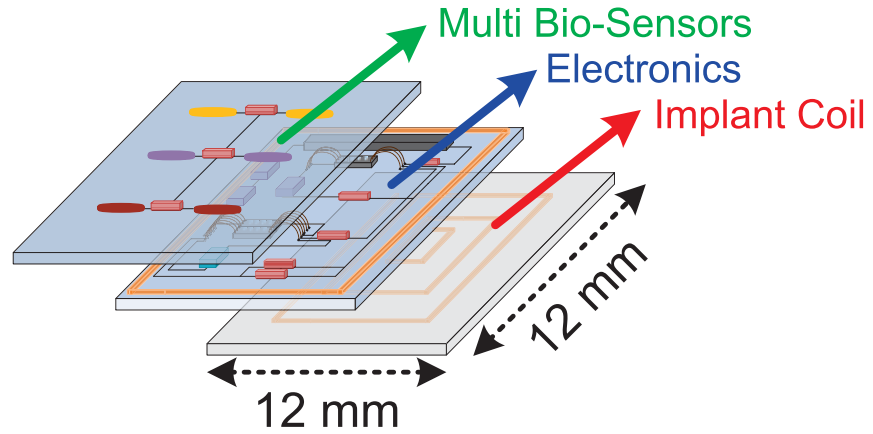

Fig. 4. Integration of the implantable bio-sensor system.

The operations in this block are depicted in Fig. 3. It takes 13 bits from the output of the Analog-Digital Converter (ADC) which corresponds to the sensor current and 9 bits from the waveform generator which corresponds to the applied voltage to the sensor. The three most significant bits of the data of four consequent data gives the 9-bit applied voltage preceded by a 3-bit starting pattern.

An $8 b / 10 b$ channel encoding is used in the Tx/Rx unit to convert the data to achieve DC balancing and avoid long sequences of the same logic value. Each data stream includes 22 bits: 20 bits coded data, 1 start bit as " 0 ", and 1 stop bit as "1". This data stream modulates the input of a low-power OOK transmitter. The power amplifier remarkably increases the overall power consumption of the implantable system. Therefore, using a power amplifier is avoided since the communication distance is short, less than $30 \mathrm{~cm}$. A freely running LC-tank oscillator is implemented as low-power transmitter [23]. Moreover, the inductance of the oscillator is designed as transmitting loop antenna to reduce the number of off-chip components. Therefore, the loop antenna is optimized for data communication at $869 \mathrm{MHz}$. The data transmission from $45 \mathrm{~cm}$ communication distance with up to $1.5 \mathrm{Mbps}$ of data rate is achieved by using the OOK transmitter which consumes only $320 \mu \mathrm{W}$. The measured Bit Error Rate (BER) is less than $1.5 \times 10^{-4}$ for $30 \mathrm{~cm}$ communication distance at $1 \mathrm{Mbps}$ data rate.

\section{Bio-Sensors}

The sensing platform which allows to monitor biological parameter of the body is placed on the top of the implantable system. The microfabrication of the passive sensing platform was realized with a two-masks process flow. Metalizations are made in $\mathrm{Pt}$ and passivation in $\mathrm{Al}_{2} \mathrm{O}_{3}$. Details on the process flow can be found in [24]. The platform measures $12 \times 11 \mathrm{~mm}$ in order to fit the size of the coil $(12 \times 12 \mathrm{~mm})$ and the wire bonding. The platform hosts an array of four working electrodes (WEs), sharing a common counter electrode (CE) and a reference electrode (RE), with the addition of a temperature sensor and a $\mathrm{pH}$ sensor [25].

\section{E. Assembly and Packaging of the Implantable System}

The implantable bio-sensor system is composed of 3 layers. Fig. 4 shows the integration of the implantable bio-sensor system. The implant coil is placed on the bottom layer 


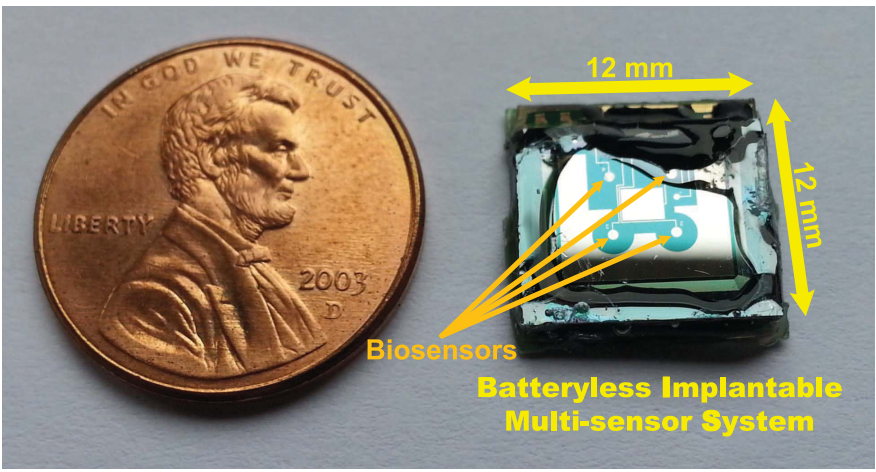

Fig. 5. Assembled implantable device.

PCB to induce the current. The second layer PCB houses two CMOS ICs and off-chip components such as storage capacitors. The radiation efficiency of an antenna is proportional to its effective area. Accordingly, the transmitting antenna of the data transmitter is optimized and designed as a loop antenna on the second layer PCB. The bio-sensors are fabricated on the passive platform. The epoxy adhesive (EP42HT-2Med system) was used to assembly the passive platform with the second layer PCB. The interconnections between the platinum pads of the passive chip and the gold pads on the PCB were realized with Al wire bonding and were protected with a glob top protection of $0.3 \mathrm{~mm}$. A $10 \mu \mathrm{m}$ layer of Parylene $\mathrm{C}$ was deposited by chemical vapor deposition using a Comelec C-30-S Parylene Deposition System. Parylene C was used to cover the whole device but not the electrode array that needs to be in contact with fluids. A bio-compatible Silicone (NuSil MED-6233) was used to cover the edges and to fill the spaces between the platform and the PCB. A 30 days of in-vivo experiment also verifies the bio-compatibility of the package with the low inflammation level at the implant site [25]. Fig. 5 shows the photograph of the assembled implantable device.

The ICs and the sensing platform were designed in parallel in order to assure a correct integration in term of: compatibility of the dimensions between the sensing platform and the antenna; compatibility of the methods for sensor functionalization with the presence of the electronics and the antenna in the same device; compatibility of the current ranges that are produced by the reaction happening at the sensing platform, with the read-out IC. The latest was the most challenging issue, because the current ranges can greatly change according to the electrode size and the functionalization, e.g. the presence of nano-structured materials, proteins, mediators, membranes, etc. However, we solved this problem by finding the right combination of nano-materials, and proteins for each molecule of interest [25]. Moreover, the integration of the ICs on the PCB is another important challenge for the system implementation. The digital block of the read-out IC requires to have $1.8 \mathrm{~V}$ voltage supply with a small ramp-up time. There is a trade-off between the start-up stabilization of the digital block and the required duration to achieve reliable measurement. Therefore, the storage capacitors are chosen carefully. If the large capacitors are used, the system cannot initialize properly. However, the large capacitors supply the required power for longer duration.

\section{Servo-Controlled Wireless Power Transfer}

The animal should move freely inside living space for the reliability of the measurement and the power must be transferred to the implantable system while the animal moves freely. Some previous studies have presented that the power can be transferred to a batteryless implantable system by using smart remote powering systems while the animal moves freely inside the living space [26]-[28]. These systems have an array of coils under the cage. Accordingly, the systems are based on tracking the animal inside the living space and turning on the most appropriate powering coil according to position of the animal. However, the power transfer efficiency decreases drastically when the animal moves towards to the edges of the powering coil. Moreover, the power transfer to the implantable system interrupts when the animal moves from one powering coil to other powering coil. In order to avoid the interrupts, the number of the powering coils can be increased to recover dead-zones where the power transfer efficiency is less than $1 \%$. However, adding powering coils on the array creates undesired coupling between powering coils which degrades the wireless power transfer efficiency. Therefore, the transmitted power needs to be increased to keep the received power at the constant level by the implantable system.

This study proposes a servo-controlled wireless power transfer system to transfer the power efficiently [29], [30]. The servo-controlled system can track the animal inside the living space and moves the powering coil under the animal position. A permanent magnet is placed in the implantable system. The magnetic field sensors are used to monitor the animal position and movement on the powering coil. Accordingly, servo-controlled $\mathrm{x}$ and $\mathrm{y}$ rails move the powering coil in order to keep the coupling between the implantable system and powering coil at maximum level.

The length of the $x$ and $y$ rails are $200 \mathrm{~mm}$ and $350 \mathrm{~mm}$, respectively [31]. The rails are sufficient to cover all the bottom of the conventional rodent cages and track the animal in the cage. In this study, we also used a conventional cage which has a bottom size of $180 \times 340 \mathrm{~mm}^{2}$. Moreover, each rail has 255 positioning step. Therefore, the animal can be tracked with the resolution of $1.37 \mathrm{~mm}$. The rails move at the speed of $30 \mathrm{~cm} / \mathrm{s}$ where the animal can move at the average speed of $7 \mathrm{~cm} / \mathrm{s}$ [15]. Additionally, the response time of the rails is $5 \mathrm{~ms}$. When the servo-controlled system is initialized, it takes less than 75 seconds to sweep all the bottom of the cage and locate the animal in the cage. The movement of the rails is adaptable according to the animal movement. The speed and acceleration/deceleration of the rails and the distance to move are also adjustable. The servo-controlled power transfer system can be easily customized for the bigger rodent animals with large-scale cages by changing the rails sizes. However, the initial localization of the animal will take more time since the living area will be increased. This duration can be reduced by replacing a larger magnet in the implantable system.

Many studies show that the rodents spend most of the time in a horizontal position (on their four feet) [15], [32]. 
In addition, the servo-controlled system also takes into account that the animal stands up on its hind legs to groom and explore the area. This action takes around $5 \mathrm{~s}$ according to the several videos which are recorded in laboratory environment. The servo-controlled system detects that the animal stands up according to the outputs of the magnetic field sensors. Therefore, the system waits for $5 \mathrm{~s}$ to ensure the animal returns to its previous position. If the delay of $5 \mathrm{~s}$ elapsed and the sensors outputs do not change, the servo-controlled $\mathrm{x}$ and $\mathrm{y}$ rails start to move the powering coil to relocate the animal by checking the nearby, the latest known position of the animal.

The power transfer efficiency of the magnetically coupled coils have dependency on the distance. Therefore, the powering and the implant coils need to be optimized for maximum power transfer efficiency at $3 \mathrm{~cm}$ [20]. The sizes of the powering and the implant coils are found as $80 \times 80 \mathrm{~mm}$ and $12 \times 12 \mathrm{~mm}$, respectively. A class-E power amplifier is designed as a coil driver to amplify the remote powering signal. The class-E is chosen due to its high drain efficiency and optimized at $13.56 \mathrm{MHz}$ to achieve maximum power transfer from the optimized remote powering link [20].

\section{Short-RAnge Data Communication \& ANDROID INTERFACE}

The sensor data is received and processed by an external reader. The external reader has two main blocks for short range communication: a custom designed data receiver and a Bluetooth module.

\section{A. Custom Designed Data Receiver}

The OOK transmitter is a LC tank oscillator to reduce the power consumption. However, the operation frequency of the transmitter drifts due to the temperature and environment change. Therefore, a custom designed data receiver is used to compensate the frequency drifts in the transmitter.

The block diagram of the data receiver is shown as Fig. 2. The receiver is implemented as superheterodyne receiver to use filter which has high quality factor to suppress the redundant signals. A custom dipole receiver antenna is designed to have better antenna gain at the operation frequency. A band select filter follows the antenna with a large bandwidth to compensate the frequency drift. A low-noise amplifier (LNA) is used to amplify the received RF signal. A mixer downconverts the received signal to a lower frequency where the filter has better quality factor than RF frequency. RF bursts are used to transmit bit " 1 " in the OOK transmitter of the implantable system. A logarithmic amplifier changes its output according to its RF input power level. Accordingly, a logarithmic amplifier is used to convert the received RF burst to a corresponding DC voltage which creates the bit " 1 ". The log-amp drives a comparator which generates the bit stream of the received sensor data. Fig. 6 shows the received sensor data streams of the implantable system.

\section{B. Bluetooth Module \& Android Interface}

The implantable system has on-board a front-end IC that provides the $8 / 10$ bit coded information of the current signal

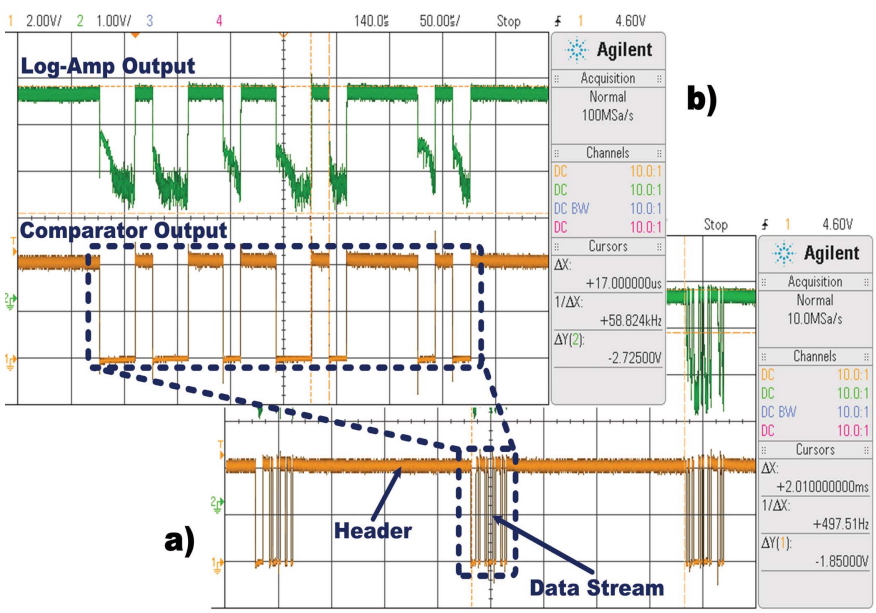

Fig. 6. (a) Received data streams of the implantable system (b) A 8/10 bit coded digital word of 20 bits.

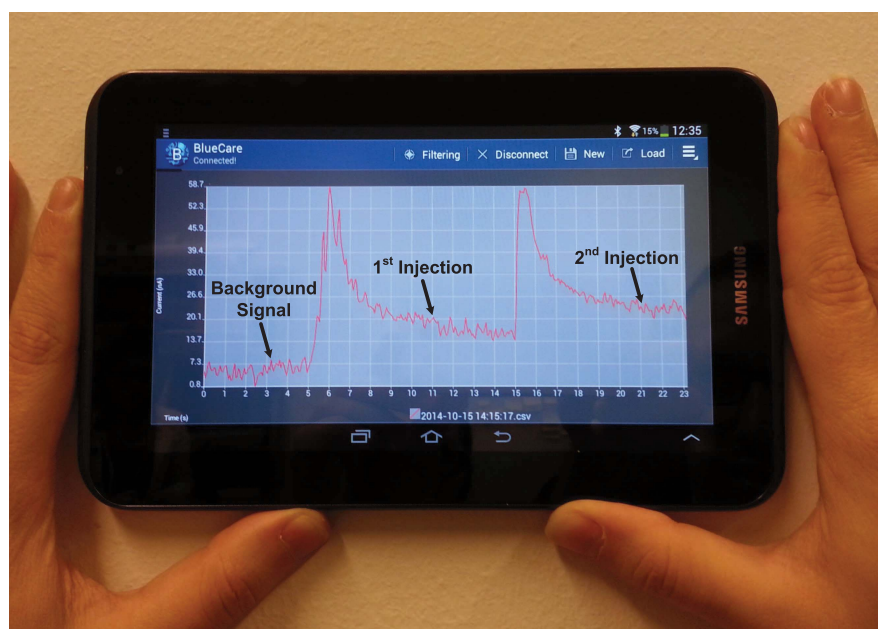

Fig. 7. Continuous bio-monitoring application on the Android interface

flowing inside the bio-sensors as a digital word of 20 bits as shown in Fig. 6. The digital word is generated at the output of the external data receiver and transmitted to the Bluetooth module. The Bluetooth module is in charge of analyze, validate and transmit via Bluetooth the data to the Android interface. An on-board microcontroller is able to sample each bit of the digital signal (Data-out), decode it and understand if a transmission error has occurred. When the data has been validated, it is transmitted by the well-known UART protocol to a commercial Bluetooth transceiver as a word of two bytes. The Bluetooth transceiver helps to communicate with a mobile device and display the measurement in real-time.

In order to allow a continuous monitoring of the concentration of the measured substances, an Android application has been developed. The communication and the data transmission between the mobile device and the sensor is carried in a wireless manner exploiting the Bluetooth technology. Starting from a previous work [33], the application is now improved by the addition of noise filtering possibilities of real time data (moving average, median value, IIR filter, etc.). The application can, therefore, receive and plot a large amount of data by optimizing space occupation in the external memory of the device, which could be added on any tablet or smart-phone. Fig. 7 shows the continuous bio-monitoring application on the 


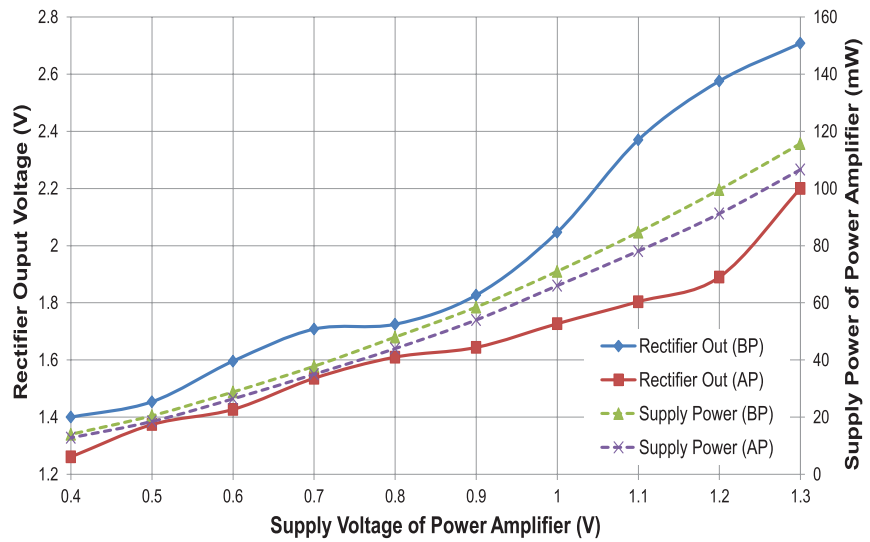

Fig. 8. Packaging effect on the remote powering performance. (BP: Before Packaging \& AP: After Packaging).

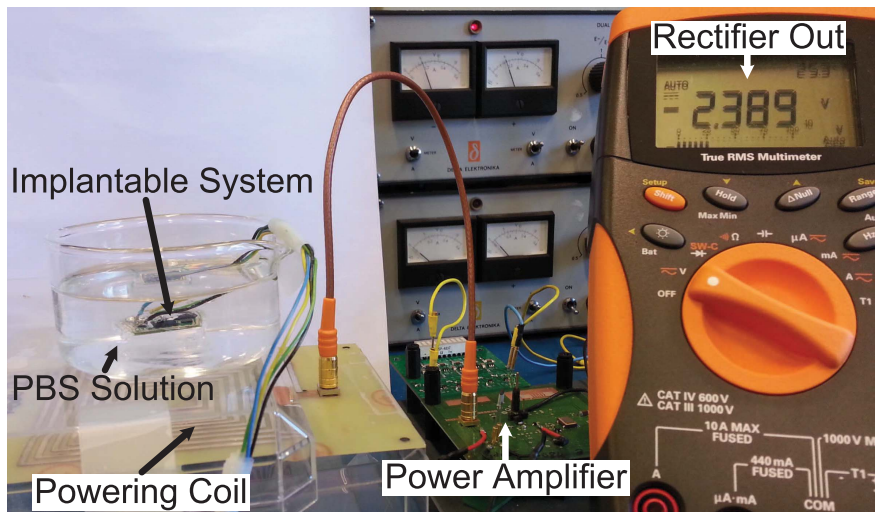

Fig. 9. Test setup for the long-term characterization of the implantable system.

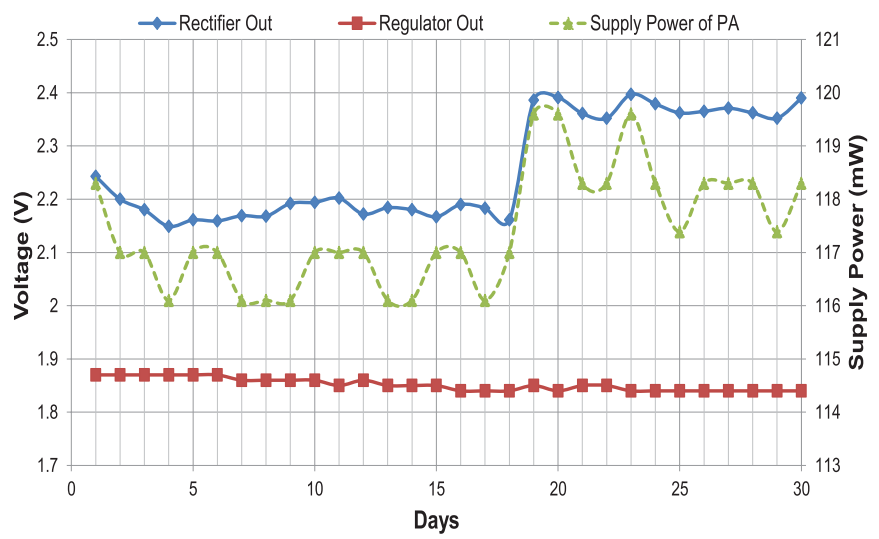

Fig. 10. Long-term in-vitro characterization results of the implantable system.

Android interface and two consecutive injections of the drug Paracetamol in the testing solution result in two consecutive current steps (in chronoamperometry at $650 \mathrm{mV}$ ) that are displayed in real-time on the screen.

\section{PACKAging \& LONG-TERM CHARACTERIZATION OF IMPLANT}

For the long-term measurements, the same procedure was followed as aforementioned for the packaging of the

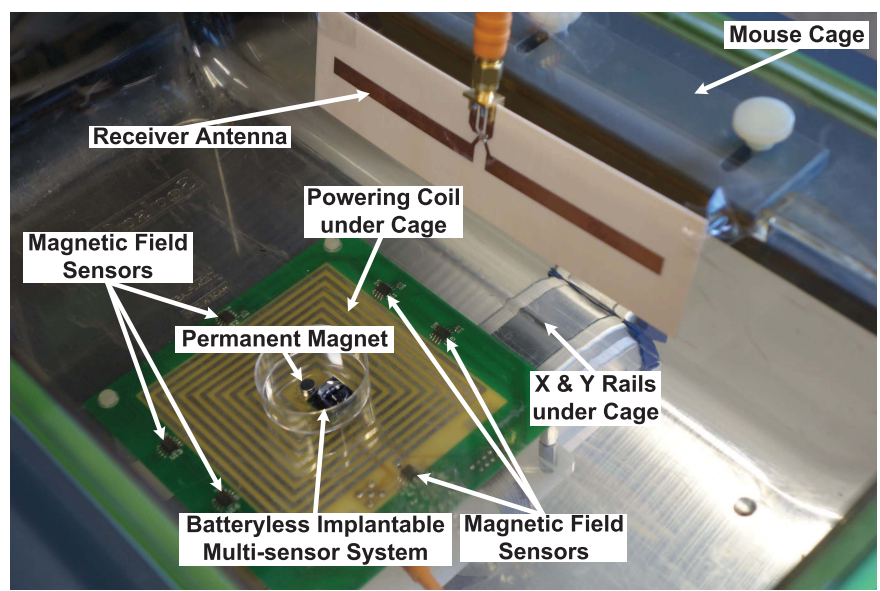

Fig. 11. Continuous long-term monitoring system for freely moving rodents.

TABLE I

SuMmary of REMOTELy POWERED IMPLANTABLE Bio-SENSOR SySTEM

\begin{tabular}{|c|c|c|}
\hline Parameter & Unit & Value \\
\hline Technology & - & CMOS $0.18 \mu \mathrm{m}$ \\
\hline Implantable & - & Yes \\
\hline Battery & - & No \\
\hline Weight & $\mathrm{g}$ & $0.92^{\star}$ \\
\hline Volume & $\mathrm{cm}^{3}$ & $0.4^{\star}$ \\
\hline Total power consumption & $\mathrm{mW}$ & 1.5 \\
\hline Powering type & - & Remote powering \\
\hline Powering frequency & $\mathrm{MHz}$ & 13.56 \\
\hline Powering distance & $\mathrm{mm}$ & 30 \\
\hline Powering efficiency & $\%$ & $16.8^{\diamond} @ 1.7 \mathrm{~mW}$ load \\
\hline Rectifier power efficiency & $\%$ & $80 @ 2$ mW load \\
\hline Voltage regulator PSRR & $\mathrm{dB}$ & $60 @ 27.12 \mathrm{MHz}$ \\
\hline Supply voltage & $\mathrm{V}$ & 1.8 \\
\hline Reference voltage PSRR & $\mathrm{dB}$ & $78.6 @ \mathrm{DC}$ \\
\hline PoR enable/disable voltage & V & $1.48 / 1.45$ \\
\hline Channel dynamic range & $\mathrm{dB}$ & 48 (1-mode) \\
\hline Chan. linear current range & $\mathrm{nA}$ & \pm 1650 \\
\hline Channel sensitivity & $\mathrm{nA}$ & 13 \\
\hline Data communication & - & OOK \\
\hline Communication frequency & $\mathrm{MHz}$ & 869 \\
\hline Communication data rate & $\mathrm{Mb} / \mathrm{s}$ & up to 1.5 \\
\hline Communication distance & $\mathrm{cm}$ & 30 \\
\hline Comm. bit error rate & - & $1.5 \times 10^{-4} @ 1 \mathrm{Mbps}$ \\
\hline
\end{tabular}

implantable system, except for the assembly with the passive sensing-platform, as no electrochemical measurements were needed. Therefore, we added the packaging only on the PCBs with the implant coil and the second layer which houses electronic circuits and off-chip components. Fig. 8 shows the effect of packaging on the remote powering performance. The packaging adds more parasitics on the implant coil which reduces the power transfer efficiency. Therefore, after the implantable system is packaged, a higher transmit power is required to achieve same voltage level at the rectifier output.

The implantable system was dip in PBS solution continuously for 30 days to characterize the system. The PBS solution is the standard buffer solution that simulates biological fluids and that has the same $\mathrm{pH}$ of human blood ( $\mathrm{pH}$ 7.4). In order to verify the packaging for the long-term characterization of the system, a test setup is used as shown in Fig. 9. 
TABLE II

PERFORMANCE COMPARISON OF MICRO-BIO-SYSTEMS

\begin{tabular}{|c|c|c|c|c|c|}
\hline Bio-system & $\begin{array}{c}\text { TBioCAS } 09 \\
{[36]}\end{array}$ & $\begin{array}{c}\text { JSSC 09 } \\
{[37]}\end{array}$ & $\begin{array}{c}\text { Sensor J. } 10 \\
{[38]}\end{array}$ & $\begin{array}{c}\text { JSSC 14 } \\
\text { [39] }\end{array}$ & This Work \\
\hline Application & Glucose monitoring & Drug screening & Animal telemetry & DNA analysis & Animal telemetry \\
\hline System Functionality & Bio-sensing & Bio-sensing & Bio-MEMS & Bio-sensing & Bio-sensing \\
\hline Technology (CMOS) & $0.18 \mu \mathrm{m}$ & $0.5 \mu \mathrm{m}$ & $1.5 \mu \mathrm{m}$ & $0.13 \mu \mathrm{m}$ & $0.18 \mu \mathrm{m}$ \\
\hline Supply voltage & $1.8 \mathrm{~V}$ & $3 \mathrm{~V}$ & $2 \mathrm{~V}, 3 \mathrm{~V}$ & $1.2 \mathrm{~V}$ & $1.8 \mathrm{~V}$ \\
\hline Total system power cons. & $\approx 0.2 \mathrm{~mW}$ & $6 \mu \mathrm{W}$ & $0.3 \mathrm{~mW}$ & $\approx 1.5 \mathrm{~mW}$ & $1.5 \mathrm{~mW}$ \\
\hline Total system weight & - & - & $0.3 \mathrm{~g}^{\star}$ & - & $0.92 \mathrm{~g}$ \\
\hline Total system volume & $32 \mathrm{~mm}^{3}$ & - & $41 \mathrm{~mm}^{3 \star}$ & - & $0.4 \mathrm{~cm}^{3}$ \\
\hline Powering type & Remote powering & 一 & Remote powering & - & Remote powering \\
\hline Powering frequency & $13.56 \mathrm{MHz}$ & - & $4 \mathrm{MHz}$ & - & $13.56 \mathrm{MHz}$ \\
\hline Powering distance & $40 \mathrm{~mm}$ & - & - & - & $30 \mathrm{~mm}$ \\
\hline Data communication & LSK & No & FSK & UWB & OOK \\
\hline Communication frequency & $13.56 \mathrm{MHz}$ & - & $433 \mathrm{MHz}$ & $3-10.6 \mathrm{GHz}$ & $869 \mathrm{MHz}$ \\
\hline Communication data rate & - & - & $48 \mathrm{Kbps}$ & $10 \mathrm{Mbps}$ & up to $1.5 \mathrm{Mbps}$ \\
\hline Communication distance & $4 \mathrm{~cm}$ & - & $15 \mathrm{~cm}$ & $5 \mathrm{~cm}$ & $30 \mathrm{~cm}$ \\
\hline Comm. bit error rate & - & - & - & - & $15 \cdot 10^{-5} @ 1 \mathrm{Mbps}$ \\
\hline Sensor type & Chemical & Chemical & Mechanical & Chemical & Chemical \\
\hline Sensing protocol & CA & IS & Pressure & $\mathrm{CV}$ & CA \\
\hline \multirow[t]{2}{*}{ Type of electrodes } & 2D Flat & $2 \mathrm{D}$ & - & 2D Flat, 3D & 2D Flat \\
\hline & Gold & Gold & - & Nanostructured gold & Platinum \\
\hline Label-free & - & No & - & Yes & Yes \\
\hline PCR-free & - & No & - & Yes & Yes \\
\hline Biomolecule type & Glucose & Protein & 一 & DNA & Paracetamol \\
\hline Concentration & $0-40 \mathrm{mM}$ & $1 \mu \mathrm{M}$ & - & $10 \mathrm{aM}-10 \mu \mathrm{M}$ & up to $3 \mathrm{mM}$ \\
\hline
\end{tabular}

The rectifier output, the regulator output voltages and the supply power of the power amplifier is monitored for 30 days. Fig. 10. shows the long-term in-vitro characterization results of the implantable system. The packaging ensures the protection of the implantable system from the corrosion by the in-vitro measurement. There is a step-up in the supply power, hence in the rectifier output voltage as indicated in Fig. 10. The reason for the step-up is that the temperature has changed in the laboratory of the test setup after 18 days.

\section{Vi. Case Study: Continuous Long-Term MONITORING FOR FREELY MOVING RODENTS}

The performance of the implantable system for continuous long-term monitoring is measured by the test setup as shown in Fig. 11. The implantable system is placed in a cage and the permanent magnet is also installed to track the implantable system inside the cage.

The servo-controlled wireless power transfer system helps to locate the batteryless implantable system inside the cage and moves the powering coil to activate the implantable system for monitoring of the human metabolites. The metallic parts of the servo-controlled system are made of aluminum which is a paramagnetic material as shown in Fig. 11. Accordingly, the power transfer efficiency is not extremely affected.

The implantable system is moved randomly to emulate the moving of the animal. The servo-controlled wireless power transfer system is verified to track the implantable system and transfer the power to the implantable system efficiently. The human metabolites are injected on bio-sensors which is fixed on the implantable system. The current is measured by the bio-sensors and the measurement data is transmitted from the implantable system to the external reader. In addition, the data is processed by the microcontroller and displayed on the Android interface in real-time.
The previous studies indicate that $20 \mathrm{~mW} / \mathrm{cm}^{2}$ of heat flux increases the temperature as $1{ }^{\circ} \mathrm{C}$ of the surrounding tissues which is defined as the safety precaution limit [34], [35]. The maximum heat flux which is generated by the powering coil (assuming the coil driver has 100\% power efficiency and $2.4 \mathrm{~V}$ rectifier output voltage is required) can be calculated by:

$$
\frac{P_{\text {Coil }}}{A_{\text {Coil }}}=\frac{120 \mathrm{~mW}}{64 \mathrm{~cm}^{2}}=1.875 \mathrm{~mW} / \mathrm{cm}^{2}
$$

where $\mathrm{P}_{\text {Coil }} \mathrm{A}_{\text {Coil }}$ are the power dissipated by the powering coil and the surface area of the coil, respectively. Accordingly, the heat flux generated by the powering coil is sufficiently low to fulfill the safety regulations.

Table I summarizes the performance of the remotely powered implantable bio-sensor system. Furthermore, Table II compares this work with the recently reported micro-bio-systems in the literature. This work offers a batteryless implantable micro-system solution for long-term bio-monitoring. The micro-system includes both the efficient power transfer and the low-power data communication compared to the previous studies. Moreover, the micro-system weighs $0.92 \mathrm{~g}$ which meets the weight requirement for the animal telemetry applications.

\section{A. Measurement With Paracetamol}

The implantable system is tested in-vitro prior to be validated in-vivo. For the measurement with the drug Paracetamol, after a cleaning with Acetone and Isopropanol, the electrodes were used without modifications. Paracetamol was pursued from Sigma-Aldrich (Switzerland), and dissolved in Ethanol ( $\geq 99.8 \%$ purity). Electrodes were tested for Paracetamol sensitivity with chronoamperometry at $+650 \mathrm{mV}$. The sensors were covered with $100 \mu l$ of a $100 \mathrm{mM}$ phosphate buffered saline (PBS) solution (pH 7.4), and then 


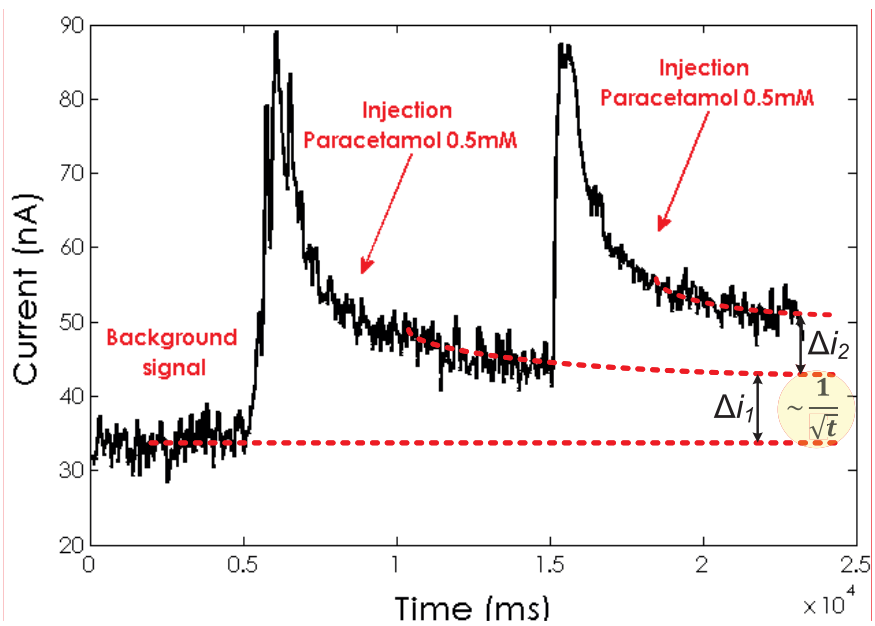

Fig. 12. Measurement with Paracetamol.

Paracetamol $0.5 \mathrm{mM}$ was injected. After each use, the chip surface was rinsed in MilliQ water and dried in air.

Paracetamol (Acetamonophen) is a well-known antiinflammatory drug. Moreover, paracetamol is also an electroactive species that can be oxidized at a constant potential of $+650 \mathrm{mV}$. At this potential Paracetamol is transformed into its oxidized form, $N$-acetyl-p-benzoquinoneimine [40]. The initial current value (background signal) related to PBS is considered as the baseline, so that the successive values of current are referred to the baseline value ( $\Delta i_{1}$ and $\Delta i_{2}$ in Fig. 12). The net current flowing through the cell is described by Cottrell's equation as follow:

$$
i(t)=\frac{n F A C \sqrt{D}}{\sqrt{\pi t}}
$$

where $n$ is the number of electrons involved in the redox reaction, $F$ is the Faraday constant, $A$ is the area of the electrode, $\mathrm{C}_{R}$ is the reduced concentration of the species, and $\mathrm{D}_{R}$ is the diffusion coefficient of the species. Current decays over the time and it reaches an approximative steady-state after a certain time, which amplitude is proportional to $C_{R}$ [41]. In Fig. 12 the current generated by two successive injections is depicted. The current decays quite fast (less than $10 \mathrm{~s}$ ), due to the miniaturization of the electrode dimensions. Moreover, two successive injections of the same amount of paracetamol result in a similar increase of the current with respect to the baseline.

\section{CONCLUSION}

This work has the aim of developing a fully implantable and remotely powered platform for the real-time monitoring of human metabolites. The paper presents a system for wireless power transfer and data communication of bio-sensor systems implantable in small animals. The batteryless implantable system is activated by remote powering at $13.56 \mathrm{MHz}$. The servo-controlled power transmitter moves under the animal moving space and transfers the power efficiently to the implantable system. The implantable system is composed of the power management, the control \& read-out, the data communication circuits and the bio-sensors.
The overall weight and size of the implantable system are $0.92 \mathrm{~g}$ and $0.4 \mathrm{~cm}^{3}$, respectively. The induced $\mathrm{AC}$ voltage on the implant coil is converted to DC voltage with a full-wave integrated rectifier and the voltage regulator supplies $1.8 \mathrm{~V}$ for the implantable system. The sensor control and read-out circuit measures the current on the bio-sensors and drives the input of the OOK transmitter. The sensor data is received by the custom designed receiver from $30 \mathrm{~cm}$ distance at $869 \mathrm{MHz}$. The measurement results are displayed on the Android interface by a tablet computer in real-time continuously. The long-term characterization of the implantable system is verified by a fully bio-compatible packaged implant with 30 days measurement. Moreover, the packaging effect on the remote powering performance is shown. A case-study on drug monitoring is also presented to prove the overall system performance with experimental in-vitro measurement.

\section{ACKNOWLEDGMENT}

The authors thank to K. Kapucu, K. Ture, G. Yilmaz and G. Surrel for their valuable feedback and help.

\section{REFERENCES}

[1] J. Ohta, T. Tokuda, K. Sasagawa, and T. Noda, "Implantable CMOS biomedical devices," Sensors, vol. 9, no. 11, pp. 9073-9093, 2009.

[2] M. C. Shults, R. K. Rhodes, S. J. Updike, B. J. Gilligan, and W. N. Reining, "A telemetry-instrumentation system for monitoring multiple subcutaneously implanted glucose sensors," IEEE Trans. Biomed. Eng., vol. 41, no. 10, pp. 937-942, Oct. 1994.

[3] D. A. Gough, L. S. Kumosa, T. L. Routh, J. T. Lin, and J. Y. Lucisano, "Function of an implanted tissue glucose sensor for more than 1 year in animals," Sci. Transl. Med., vol. 2, no. 42, p. 42ra53, 2010.

[4] K. Prestele, M. Franetzki, and H. Kresse, "Development of programcontrolled portable insulin delivery devices," Diabetes Care, vol. 3, no. 2, pp. 362-368, 1980.

[5] H.-M. Lee, K.-Y. Kwon, W. Li, and M. Ghovanloo, "A wireless implantable switched-capacitor based optogenetic stimulating system," in Proc. 36th Annu. Int. Conf. IEEE Eng. Med. Biol. Soc. (EMBC), Aug. 2014, pp. 878-881.

[6] P. Cong, N. Chaimanonart, W. H. Ko, and D. J. Young, "A wireless and batteryless $130 \mathrm{mg} 300 \mu \mathrm{W} 10 \mathrm{~b}$ implantable blood-pressure-sensing microsystem for real-time genetically engineered mice monitoring," in Proc. IEEE Int. Solid-State Circuits Conf., Feb. 2009, pp. 428-430.

[7] B. Yu, N. Long, Y. Moussy, and F. Moussy, "A long-term flexible minimally-invasive implantable glucose biosensor based on an epoxyenhanced polyurethane membrane," Biosensors Bioelectron., vol. 21, no. 12, pp. 2275-2282, 2006.

[8] S. Carrara et al., "Fully integrated biochip platforms for advanced healthcare," Sensors, vol. 12, no. 8, pp. 11013-11060, 2012.

[9] S. Paddeu, M. K. Ram, S. Carrara, and C. Nicolini, "Langmuir-Schaefer films of a poly(o-anisidine) conducting polymer for sensors and displays," Nanotechnology, vol. 9, no. 3, pp. 228-236, 1998.

[10] V. Erokhin, S. Carrara, H. Amenitch, S. Bernstorff, and C. Nicolini, "Semiconductor nanoparticles for quantum devices," Nanotechnology, vol. 9, no. 3, pp. 158-161, 1998.

[11] C. Baj-Rossi, G. De Micheli, and S. Carrara, "Electrochemical biochip for applications to wireless and batteryless monitoring of freemoving mice," in Proc. 36th Annu. Int. Conf. IEEE Eng. Med. Biol. Soc. (EMBC), Aug. 2014, pp. 2020-2023.

[12] Q. Wang, H. R. Brunner, and M. Burnier, "Determination of cardiac contractility in awake unsedated mice with a fluid-filled catheter," Amer. J. Physiol. Heart Circulat. Physiol., vol. 286, no. 2, p. H806-14, 2004.

[13] E. G. Kilinc et al., "Remotely powered implantable heart monitoring system for freely moving animals," in Proc. 5th IEEE Int. Workshop Adv. Sensors Interf. (IWASI), Jun. 2013, pp. 10-13.

[14] S. A. G. Willis-Owen and J. Flint, "The genetic basis of emotional behaviour in mice," Eur. J. Human Genetics, vol. 14, no. 6, pp. 721-728, 2006. 
[15] J. N. Crawley, What's Wrong With My Mouse?: Behavioral Phenotyping of Transgenic and Knockout Mice, 2nd ed. Hoboken, NJ, USA: Wiley, 2007.

[16] S. Yang et al., "Feedback controlled piezo-motor microdrive for accurate electrode positioning in chronic single unit recording in behaving mice," J. Neurosci. Methods, vol. 195, no. 2, pp. 117-127, 2011.

[17] E. Greenwald, M. Mollazadeh, C. Hu, W. Tang, E. Culurciello, and V. Thakor, "A VLSI neural monitoring system with ultra-wideband telemetry for awake behaving subjects," IEEE Trans. Biomed. Circuits Syst., vol. 5, no. 2, pp. 112-119, Apr. 2011.

[18] S.-Y. Lee et al., "A programmable implantable microstimulator SoC with wireless telemetry: Application in closed-loop endocardial stimulation for cardiac pacemaker," IEEE Trans. Biomed. Circuits Syst., vol. 5, no. 6, pp. 511-522, Dec. 2011.

[19] S. Carrara, A. Cavallini, V. Erokhin, and G. De Micheli, "Multi-panel drugs detection in human serum for personalized therapy," Biosensors Bioelectron., vol. 26, no. 9, pp. 3914-3919, 2011.

[20] E. G. Kilinc, M. A. Ghanad, F. Maloberti, and C. Dehollain, "A remotely powered implantable biomedical system with location detector," IEEE Trans. Biomed. Circuits Syst., vol. 9, no. 1, pp. 113-123, Feb. 2014.

[21] S. S. Ghoreishizadeh, S. Carrara, and G. De Micheli, "A configurable IC to control, readout, and calibrate an array of biosensors," in Proc. Eur. Conf. Circuit Theory Design (ECCTD), 2013, pp. 1-4.

[22] S. S. Ghoreishizadeh, C. Boero, A. Pullini, C. Baj-Rossi, S. Carrara and G. De Micheli, "Sub-mW reconfigurable interface IC for electrochemical sensing," in Proc. IEEE Biomed. Circuits Syst. Conf. (BioCAS), Oct. 2014, pp. 232-235.

[23] E. G. Kilinc, K. Kapucu, F. Maloberti, and C. Dehollain, "Servocontrolled remote powering and low-power data communication of implantable bio-systems for freely moving animals," in Proc. IEEE Biomed. Circuits Syst. Conf. (BioCAS), Oct. 2014, pp. 508-511.

[24] A. Cavallini, C. Baj-Rossi, S. Ghoreishizadeh, G. De Micheli, and S. Carrara, "Design, fabrication, and test of a sensor array for perspective biosensing in chronic pathologies," in Proc. IEEE Biomed. Circuits Syst. Conf., Nov. 2012, pp. 124-127.

[25] C. Baj-Rossi et al., "Full fabrication and packaging of an implantable multi-panel device for monitoring of metabolites in small animals," IEEE Trans. Biomed. Circuits Syst., vol. 8, no. 5, pp. 636-647, Oct. 2014.

[26] D. M. Russell, D. McCormick, A. J. Taberner, S. C. Malpas, and D. M. Budgett, "A high bandwidth fully implantable mouse telemetry system for chronic ECG measurement," in Proc. Annu. Int. Conf. IEEE Eng. Med. Biol. Soc. (EMBC), Aug./Sep. 2011, pp. 7666-7669.

[27] E. G. Kilinc, B. Canovas, F. Maloberti, and C. Dehollaini, "Intelligent cage for remotely powered freely moving animal telemetry systems," in Proc. IEEE ISCAS, May 2012, pp. 2207-2210.

[28] B. Lee, M. Kiani, and M. Ghovanloo, "A smart homecage system with 3D tracking for long-term behavioral experiments," in Proc. 36th Annu. Int. Conf. IEEE Eng. Med. Biol. Soc. (EMBC), Aug. 2014, pp. 2016-2019.

[29] E. G. Kilinc and C. Dehollain, "Intelligent remote powering," U.S. Patent 421374, 2014

[30] E. G. Kilinc, G. Conus, C. Weber, B. Kawkabani, F. Maloberti, and C. Dehollain, "A system for wireless power transfer of micro-systems in-vivo implantable in freely moving animals," IEEE Sensors J., vol. 14 no. 2, pp. 522-531, Feb. 2014.

[31] MISUMI Europa GmbH, RS106-C1-N-Single Axis Robot RS1. [Online]. Available: http://www.misumi-europe.com, accessed Mar. 2015.

[32] T. K. Givrad, J. M. Maarek, W. H. Moore, and D. P. Holschneider, "Powering an implantable minipump with a multi-layered printed circuit coil for drug infusion applications in rodents," Ann. Biomed. Eng., vol. 38, no. 3, pp. 707-713, 2010.

[33] J. Olivo, L. Foglia, M. A. Casulli, C. Boero, S. Carrara, and G. De Micheli, "Glucose and lactate monitoring in cell cultures with a wireless android interface," in Proc. IEEE BioCAS, Oct. 2014, pp. 400-403.

[34] T. M. Seese, H. Harasaki, G. M. Saidel, and C. R. Davies, "Characterization of tissue morphology, angiogenesis, and temperature in the adaptive response of muscle tissue to chronic heating," Lab. Invest., vol. 78, no. 12, pp. 1553-1562, 1998.

[35] W. M. Reichert, Ed., Indwelling Neural Implants: Strategies for Contending With the In Vivo Environment. Boca Raton, FL, USA CRC Press, 2007.

[36] M. M. Ahmadi and G. A. Jullien, "A wireless-implantable microsystem for continuous blood glucose monitoring," IEEE Trans. Biomed. Circuits Syst., vol. 3, no. 3, pp. 169-180, Jun. 2009.
[37] C. Yang, S. R. Jadhav, R. M. Worden, and A. J. Mason, “Compact lowpower impedance-to-digital converter for sensor array microsystems," IEEE J. Solid-State Circuits, vol. 44, no. 10, pp. 2844-2855, Oct. 2009.

[38] P. Cong, W. H. Ko, and D. J. Young, "Wireless batteryless implantable blood pressure monitoring microsystem for small laboratory animals,' IEEE Sensors J., vol. 10, no. 2, pp. 243-254, Feb. 2010.

[39] H. M. Jafari, K. Abdelhalim, L. Soleymani, E. H. Sargent, S. O. Kelley, and R. Genov, "Nanostructured CMOS wireless ultra-wideband labelfree PCR-free DNA analysis SoC," IEEE J. Solid-State Circuits, vol. 49, no. 5, pp. 1223-1241, May 2014.

[40] D. Nematollahi, H. Shayani-Jam, M. Alimoradi, and S. Niroomand, "Electrochemical oxidation of acetaminophen in aqueous solutions: Kinetic evaluation of hydrolysis, hydroxylation and dimerization processes," Electrochim. Acta, vol. 54, no. 28, pp. 7407-7415, 2009.

[41] A. J. Bard and L. R. Faulkner, Electrochemical Methods: Fundamentals and Applications, 2nd ed. New York, NY, USA: Wiley, 2000.

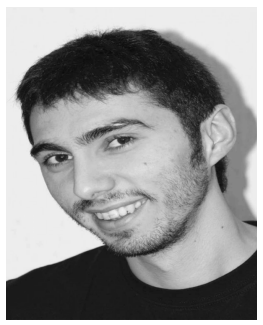

Enver G. Kilinc received the B.Sc. degree in electronics engineering from Istanbul Technical University (ITU), Turkey, in 2008, and the M.Sc. degree in electrical and electronic engineering and the Ph.D. degree in microsystems and microelectronics from the École Polytechnique Fédérale de Lausanne (EPFL), Switzerland, in 2010 and 2014 respectively. In 2010, he joined the Electronics Laboratory, EPFL, as a Research Assistant in the field of RFIC design. He was a Post-Doctoral Fellow with the Electronics Laboratory in 2015. He is currently a Post-Doctoral Fellow in wireless power transmission and implantable biomedical system design with the Advance Digital Systems Laboratory, University of Toronto, Toronto, ON, Canada. His research interests include RF CMOS circuit design for wireless sensor systems and biomedical applications.

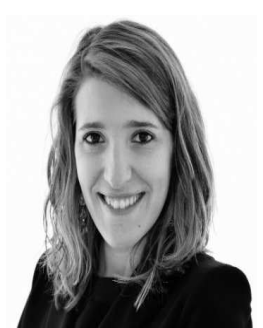

Camilla Baj-Rossi received the bachelor's degree and the master's degree in biomedical engineering from the Politecnico di Torino, Italy, in 2008 and 2010, respectively. She is currently pursuing the Ph.D. degree in microsystems and microelectronics with the Laboratory of Integrated System (LSI) under the direction of S. Carrara and G. De Micheli. She carried out her master's project with LSI, École Polytechnique Fédérale de Lausanne, working on the design of a multipanel biochip based on P450 and CNT for drugs monitoring in personalized therapy.

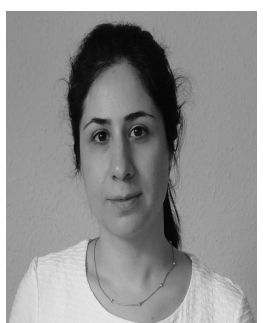

Sara Ghoreishizadeh received the B.Sc. degree in electrical engineering and the M.Sc. degree in microelectronics from the Sharif University of Technology, in 2007 and 2009, respectively, and the $\mathrm{Ph} . \mathrm{D}$. degree from the École Polytechnique Fédérale de Lausanne, in 2015. She is currently a Post-Doctoral Researcher with the Centre for Bioinspired Technology, Imperial College London. The focus of her research is lowpower analog/mixed-signal readout IC design for implantable medical devices. 


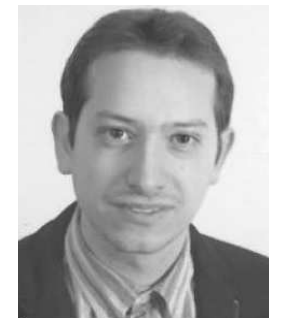

Stefano Riario received the M.Sc. degree in electronics engineering from the Politecnico di Torino, Italy, in 2013. After one year as a Scientific Collaborator with the School of Engineers and Architects of Fribourg, Switzerland, she is working as a Scientific Assistant with the Laboratory of Integrated Systems, École Polytechnique Fédérale de Lausanne, Lausanne, Switzerland.

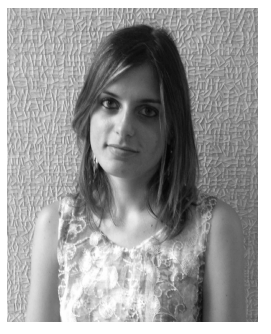

Francesca Stradolini received the M.Sc. degree in biomedical engineering from the University of Genova, Italy, in 2015. She carried out her master's thesis with the École Polytechnique Fédérale de Lausanne (EPFL), Lausanne, Switzerland, working on the development of an Android interface for the wireless and continuous monitoring of metabolites. Moreover, she got the Advanced Studies in Information Technologies and Communication Certificate in 2012. She is currently a Doctoral Assistant with the Integrated System Laboratory, EPFL. Her research interests include the development of a nonimplantable prototype for the monitoring of multiple anesthesiology drugs in human blood with the total realization of the sensing platform, microfluidics system, and the software development.

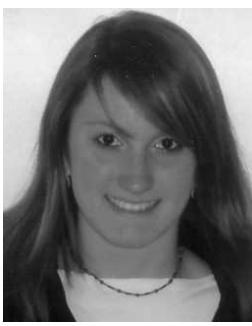

Cristina Boero received the M.Sc. degree in biomedical engineering from the Politecnico di Torino, Italy, in 2007, and the Ph.D. degree in microsystems and microelectronics from the École Polytechnique Fédérale de Lausanne, Lausanne, Switzerland, in 2012. She is currently with Bio-Rad Laboratories as a System Engineer. When she was with the Laboratory of Integrated Systems with Prof. De Micheli and Dr. S. Carrara, her research interests include electrochemical biosensors for the detection of metabolites in stem cell cultures. She received the Gold Leaf Award at PRIME in 2009.

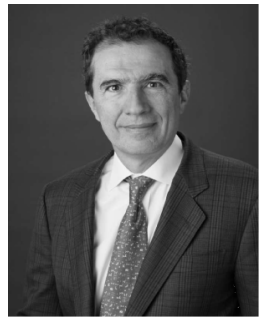

Giovanni De Micheli (F'94) received the Nuclear Engineering degree from the Politecnico di Milano, in 1979, and the M.S. and Ph.D. degrees in electrical engineering and computer science from the University of California at Berkeley, in 1980 and 1983, respectively. $\mathrm{He}$ is currently a Professor and the Director of the Institute of Electrical Engineering and the Integrated Systems Centre, École Polytechnique Fédérale de Lausanne, Switzerland. He is the Program Leader of the Nano-Tera.ch program. $\mathrm{He}$ was a Professor of Electrical Engineering with

Stanford University.

$\mathrm{He}$ is also interested in heterogeneous platform design including electrical components and biosensors, and data processing of biomedical information. He has authored a book entitled Synthesis and Optimization of Digital Circuits (McGraw-Hill, 1994), and co-authored and/or co-edited eight other books and over 600 technical articles. His citation is an h-index of 85 according to a Google Scholar. His research interests include several aspects of design technologies for integrated circuits and systems, such as synthesis for emerging technologies, networks on chips, and 3-D integration. He is a member of the Scientific Advisory Board of IMEC (Leuven, B), CfAED (Dresden, D), and STMicroelectronics. He is a fellow of the Association for Computing Machinery and a member of the Academia Europaea.

Prof. De Micheli was a recipient of the 2012 IEEE/CAS Mac Van Valkenburg Award for contributions to theory, practice, and experimentation in design methods and tools and the 2003 EEE Emanuel Piore Award for contributions to computer-aided synthesis of digital systems. He also received the Golden Jubilee Medal for outstanding contributions to the IEEE CAS Society in 2000, the D. Pederson Award for the best paper on the IEEE TRANSACTIONS ON CAD/ICAS in 1987, and several best paper awards, including DAC (1983 and 1993), DATE (2005), and Nanoarch (2010 and 2012).

He served the IEEE in several capacities, namely, the Division 1 Director (2008-2009), the Co-Founder and President Elect of the IEEE Council on EDA (2005-2007), the President of the IEEE CAS Society (2003), and the Editor-in-Chief of the IEEE TRANSACTIONS ON CAD/ICAS (1997-2001). He was the Chair of several conferences, including Memocode (2014), DATE (2010), pHealth (2006), VLSI SOC (2006), DAC (2000), and ICCD (1989).

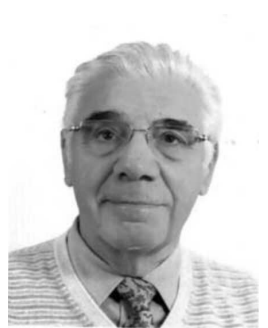

Franco Maloberti (F'96) received the Laurea (summa cum laude) degree in physics from the University of Parma, Italy, in 1968, and the Dr. Honoris Causa degree in electronics from Inaoe, Puebla, Mexico, in 1996. He was a Visiting Professor with ETH-PEL, Zurich, in 1993, and EPFL-LEG, Lausanne, in 2004. He was a Professor of Microelectronics the Head of the Micro Integrated Systems Group with the University of Pavia, Pavia, Italy, TI/J.Kilby Analog Engineering Chair Professor with Texas A\&M University, and the Distinguished Microelectronic Chair Professor with the University of Texas at Dallas. He is currently a Professor with the University of Pavia, and an Honorary Professor with the University of Macau, China. His professional expertise is in the design, analysis, and characterization of integrated circuits and analogue digital applications, mainly in the areas of switched capacitor circuits, data converters, interfaces for telecommunication and sensor systems, and portable power management. He has authored over 475 published papers, five books, and holds 32 patents. He has been responsible for many research programs, including ten ESPRIT projects and served the European Commission in many European Initiatives. He served the Academy of Finland on the assessment of electronic research. He served the National Research Council of Portugal for the research activity assessment of Portuguese universities. He was a member of the Advisory Board of INESC-Lisbon, Portugal. He is the Chairman of the Academic Committee of the Microelectronics Key Laboratoty, Macau, China. He was the VP Region 8 of the IEEE CAS (1995-1997), an Associate Editor of the IEEE TRAnsactions on Circuits and Systems II, the President of the IEEE Sensor Council (2002-2003), the IEEE CAS BoG Member (2003-2005), and a VP Publications of the IEEE CAS (2007-2008). He was a DL of the IEEE SSC Society (2009-2010) and is a DL of the IEEE CAS Society. He received the 1999 IEEE CAS Society Meritorious Service Award, the 2000 CAS Society Golden Jubilee Medal, and the IEEE Millenium Medal. He was a co-recipient of the 1996 IEE Fleming Premium, the ESSCIRC 2007 Best Paper Award, and the IEEJ Workshop 2007 and 2010 Best Paper Award. 


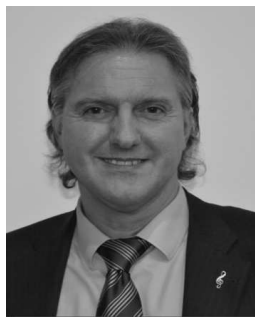

Sandro Carrara (SM'14) received the Ph.D. degree in biochemistry and biophysics from the University of Padua, Italy, the master's degree in physics from the University of Genoa, Italy, and the Diploma degree in electronics from the National Institute of Technology, Albenga, Italy. He was a Professor of Optical and Electrical Biosensors with the Department of Electrical Engineering and Biophysics, University of Genoa, Italy, and also a Professor of Nanobiotechnology with the University of Bologna, Italy. He was appointed as a CASS Distinguished Lecturer from 2013 to 2014. He is currently a Faculty Member (MER) with the École Polytechnique Fédérale de Lausanne, Lausanne, Switzerland. $\mathrm{He}$ has authored over 200 scientific publications and 12 patents. He has several Top-25 Hottest-Articles (2004, 2005, 2008, 2009, and two times in 2012) published in highly ranked international journals, such as Biosensors and Bioelectronics, Sensors and Actuators B, the IEEE SENSORS JOURNAL, and Thin Solid Films. His scientific interests are in electrical phenomena of nanobiostructured films, and CMOS design of biochips based on proteins and DNA. He is the Founder and Editor-in-Chief of the BioNanoScience (Springer) journal, a Topical Editor of the IEEE SENSORS JOURNAL, and an Associate Editor of the IEEE TRANSACTIONS ON BIOMEDICAL CiRCUITS AND SYstems. He is a member of the Board of Governors of the IEEE Circuits and Systems Society. $\mathrm{He}$ is the Member-at-Large of the IEEE Sensors Council. His work received the NATO Advanced Research Award for the original contribution to the physics of single-electron conductivity in nanoparticles in 1996, three best paper awards at the IEEE PRIME Conference in 2015 (Glasgow), 2010 (Berlin), and 2009 (Cork), the Best Poster Award at the Nanotera Workshop in 2011 (Bern), and the Best Poster Award at the NanoEurope Symposium in 2009 (Rapperswil). He also received the Best Referees Award from the journal Biosensor and Bioelectronics in 2006. From 1997 to 2000, he was a member of the International Committee at the ELETTRA Synchrotron in Trieste. From 2000 to 2003, he was the Scientific Leader of the National Research Program in the filed of nanobiotechnology. He was an Internationally Esteemed Expert of the evaluation panel of the Academy of Finland in a research program from 2010 to 2013. He has been the General Chairman of the Conference IEEE BioCAS 2014.

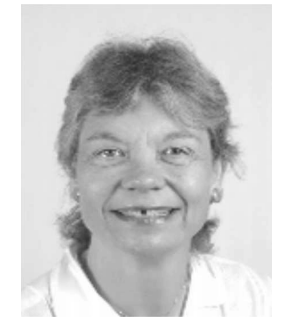

Catherine Dehollain (M'93) received the degree in electrical engineering and the Ph.D. degree from the École Polytechnique Fédérale de Lausanne (EPFL), Lausanne, Switzerland, in 1982 and 1995, respectively. From 1982 to 1984, she was a Research Assistant with Electronics Laboratories, EPFL. In 1984, she joined the Motorola European Center for Research and Development, Geneva, Switzerland, where she designed integrated circuits applied to telecommunications. In 1990, she joined EPFL as a Senior Assistant with the Chaire des Circuits et Systèmes, where she was involved in impedance broadband matching. Since 1995, she has been responsible for the RFIC Group, EPFL, for RF activities. She has been the Technical Project Manager of the European projects, CTI projects, and the Swiss National Science Foundation projects dedicated to RF wireless micropower sensor networks and mobile phones. Since 1998, she has been a Lecturer with EPFL in the area of RF circuits, electric filters, and CAD tools. Since 2006, she has been a Maítre d'Enseignement et de Recherche with EPFL. She has authored or co-authored four scientific books and 120 scientific publications. Her current research interests include low power analog circuits, biomedical remotely powered sensors, and electric filters. 